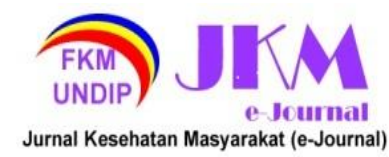

JURNAL KESEHATAN MASYARAKAT (e-Journal)

Volume 9, Nomor 6, November 2021

ISSN: 2715-5617 / e-ISSN: 2356-3346

http://ejournal3.undip.ac.id/index.php/jkm

\title{
PENGARUH PENGAPLIKASIAN VARIASI PERANGKAP TERHADAP JUMLAH LALAT TERPERANGKAP DI TEMPAT PENJUALAN IKAN PASAR TAMBAK LOROK KOTA SEMARANG
}

\author{
Choirul Azizah $^{1^{*}}$, Retno Hestiningsih ${ }^{2}$, Sri Yuliawati ${ }^{2}$, M. Arie Wuryanto ${ }^{2}$ \\ ${ }^{1}$ Peminatan Entomologi Kesehatan, Fakultas Kesehatan Masyarakat Universitas Diponegoro \\ JI. Prof. H. Soedarto, S.H.,Tembalang, Semarang, Indonesia \\ ${ }^{2}$ Bagian Epidemiologi dan Penyakit Tropik, Fakultas Kesehatan Masyarakat Universitas Diponegoro \\ Jl. Prof. H. Soedarto, S.H.,Tembalang, Semarang, Indonesia \\ *Corresponding Author: choirulazizah47@gmail.com
}

\begin{abstract}
The density of flies at the fish sales of Tambak Lorok Market, Semarang City is included in the high category with a density number of 9.35. Based on observation showed that no control has been carried out to reduce the fly population at the fish sales of Tambak Lorok Market, Semarang City. The way to control fly population is to use fly traps. The aim of study was to analyze the effect of trap variations on the number of trapped flies at the fish sales of Tambak Lorok Market, Semarang City. The type of research used was observasional with a cross sectional study design. The samples in this study were flies trapped in various types of traps (sticky trap, fly trap, bottle trap, tree flies) installed at the fish sales of Tambak Lorok Market. The result of the Kruskal Wallis test showed a significance value of 0.000 ( $\alpha$ $<0.05)$ so that there were differences in the variation of traps on the number of trapped flies. In conclusion, the fly trap that traps the most flies is the sticky trap. It is hoped that fish traders can carry out fly control to reduce fly density.
\end{abstract}

Keywords : Flies, flies trap, flies control

\section{PENDAHULUAN}

Lalat merupakan salah satu serangga pengganggu yang dapat membawa patogen pada tubuhnya. Beberapa spesies lalat yang berperan penting dalam kesehatan yaitu Musca domestica (lalat rumah), Crysomya sp (lalat sampah), Sarcophaga spp (lalat daging), dan Drosophila spp (lalat buah).(1) Perilaku lalat yang menyukai pada lingkungan kotor merupakan faktor utama munculnya foodborne disease di lingkungan masyarakat seperti typus, diare, disentri, kolera, dan muntaber.(2) Sebagai vektor mekanik, lalat memindahkan agen penyakit seperti bakteri dengan cara hinggap. Pada saat hinggap, lalat tersebut meninggalkan patogen di benda atau makanan yang dihinggapinya. Selain itu, lalat juga mengalami proses regurgitasi atau memuntahkan kembali makanan yang sudah dimakan oleh lalat. ${ }^{(3,4)}$

Aktivitas lalat seperti berkembangbiak, mencari makan, dan beristirahat selalu di tempat-tempat yang terkesan kotor dan lembab. (5) Salah satu tempat yang disukai oleh lalat adalah tempat penjualan ikan tradisional. Tempat penjualan ikan tradisional adalah tempat untuk melakukan jual beli ikan dengan tempat yang sederhana dimana penjual dan pembeli bertemu secara langsung. Tempat tersebut merupakan tempat yang mendukung untuk kelangsungan hidup lalat dimana tersedianya sumber makanan lalat yaitu ikan yang termasuk bahan mentah organik dan juga adanya sampah. Hal tersebut yang menarik lalat muncul untuk mencari makan dan berkembang biak.(6)

Berdasarkan hasil study pendahuluan yang telah peneliti lakukan pada bulan Oktober 2020 di tempat penjualan ikan Pasar Tambak Lorok Kota Semarang, dihasilkan bahwa indeks kepadatan populasi lalat adalah sebesar 9,35 yang termasuk dalam kategori tinggi.(6) Sehingga perlu upaya pengendalian untuk menurunkan populasi lalat serendah mungkin hingga keberadaannya tidak lagi berisiko dalam penularan penyakit di suatu tempat. ${ }^{(7)}$ Keadaan pasar yang kurang terawat, kotor, becek, dan ikan jualan yang diletakkan di wadah terbuka menjadi faktor utama penyebab munculnya populasi lalat di pasar tersebut selain adanya ikan yang merupakan sumber makanan untuk lalat. Sebelumnya di pasar tersebut belum dilakukan pengendalian untuk menekan populasi lalat.

Ada berbagai macam pengendalian vektor yang dapat dilakukan untuk mengurangi atau mengendalikan populasi lalat sampai pada batas yang dapat diterima yaitu pengendalian secara kimiawi, biologis, fisik maupun terpadu. ${ }^{(7)}$ Pengendalian secara kimiawi menggunakan insektisida secara terus 


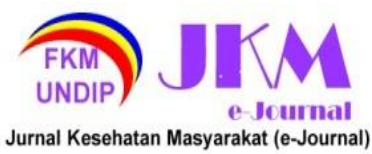

menerus dapat menyebabkan pencemaran lingkungan, meninggalkan residu pada makanan, dan berdampak negatif terhadap kesehatan manusia. Penggunaan insektisida dalam pengendalian vektor dalam jangka panjang juga dapat menyebabkan resistensi pada vektor. ${ }^{(8)}$ Oleh karena itu perlu adanya pengendalian vektor strategis agar dapat mengurangi dampak negatif yang ditimbulkan.

Pengendalian secara fisik dengan pemasangan perangkap dapat memanfaatkan berbagai media seperti media air (tempat untuk bertelur), gelombang elektromagnetik, cahaya, dan trap. Selain itu pemasangan perangkap juga dapat menggunakan umpan sebagai penarik vektor.(7) Pengendalian lalat dengan pemasangan perangkap yang biasa dilakukan oleh masyarakat adalah menggunakan kertas lem lalat. Hal itu dikarenakan lem kertas sudah dikenal oleh masyarakat serta sudah banyak dijual di pasaran.

Dari uraian di atas maka peneliti tertarik untuk melakukan penelitian tentang "Pengaruh Pengaplikasian Variasi Perangkap Terhadap Jumlah Lalat Terperangkap Di Tempat Penjualan Ikan Pasar Tambak Lorok Kota Semarang". Sehingga dengan adanya penelitian ini, selain untuk mengurangi populasi lalat juga diharapkan mampu menjadi bahan rekomendasi atau alternative untuk mengendalikan populasi lalat yang berkelanjutan dengan menggunakan perangkap lalat untuk mengurangi penggunaan bahan kimiawi. Tujuan penelitian ini adalah untuk menganalisis pengaruh pengaplikasian variasi perangkap terhadap jumlah lalat terperangkap di tempat penjualan ikan Pasar Tambak Lorok Kota Semarang.

\section{METODE PENELITIAN}

Penelitian ini merupakan penelitian observasional dengan desain study cross sectional yang dilaksanakan di tempat penjualan ikan Pasar Tambak Lorok Kota Semarang pada bulan Maret - Mei 2021. Hipotesis alternative pada penelitian ini adalah terdapat pengaruh pengaplikasian variasi perangkap terhadap jumlah lalat terperangkap di tempat penjualan ikan Pasar Tambak Lorok Kota Semarang. Sampel dalam penelitian ini adalah lalat yang terperangkap pada berbagai macam variasi perangkap lalat yang terpasang pada 4 titik di tempat penjualan ikan Pasar Tambak Lorok.

Variasi perangkap yang digunakan yaitu sticky trap, fly trap, botol trap, dan pohon lalat.
Pemasangan perangkap dipasang selama 3 jam pada rentang waktu $07.00-11.00$ WIB. Dilakukan perhitungan lalat terperangkap pada interval waktu 30 menit, 60 menit, 120 menit, dan 180 menit.

Untuk menguatkan hasil penelitian dan mengurangi kesalahan data dilakukan 6 kali pengulangan pemasangan perangkap. sebelum melakukan pemasangan perangkap, juga melakukan pengukuran parameter lingkungan suhu, kelembaban, intensitas cahaya, dan kecepatan angin untuk mengendalikan variabel pengganggu. Data yang diperoleh dari hasil penelitian dianalisis menggunakan uji Kruskal Wallis untuk mengetahui pengaruh antar variabel (derajat kepercayaan pada taraf $95 \%$ ).

\section{HASIL DAN PEMBAHASAN}

Gambaran Umum Tempat Penjualan Ikan Pasar Tambak Lorok Kota Semarang

Pasar Tambak Lorok berlokasi di wilayah pesisir Kampung Wisata Bahari Jalan Tambak Mulyo Kelurahan Tanjung Emas Kecamatan Semarang Utara Kota Semarang. Pasar ini baru diresmikan oleh Walikota Semarang pada Tahun 2019. Pasar ini dinaungi dan dikelola oleh Dinas Perdagangan Pemerintah Kota Semarang, sedangkan untuk kegiatan operasional harian pasar dikelola oleh kepala pasar dan pengurusnya. Tempat penjualan ikan berada dilantai satu Pasar Tambak Lorok. Lapak kios dan los pasar lantai satu diperuntukkan khusus untuk pedagang yang berjualan ikan basah atau kering serta daging yang terdiri atas 72 kios.

Sebelum terdapat pasar, terdapat Tempat Pelelangan Ikan (TPI) di kampung Tambak Lorok. Semua hasil tangkapan nelayan dilelang di tempat tersebut. Akan tetapi setelah dibangun pasar tersebut hasil tangkapan nelayan langsung dijual di pasar tersebut khususnya di lantai satu yang khusus untuk berjualan ikan. Para nelayan biasanya selesai mencari ikan pada siang hari dan langsung dibawa ke pasar untuk dijual.

\section{Pengukuran Parameter Lingkungan}

Pada penelitian ini dilakukan beberapa pengukuran parameter lingkungan yaitu pengukuran suhu, kelembaban, intensitas cahaya, dan kecepatan angin untuk mengendalikan variabel pengganggu di Tempat Penjualan Ikan Pasar Tambak Lorok Kota Semarang. 


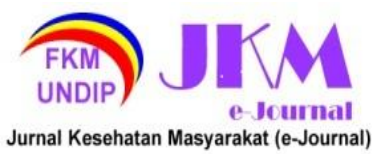

\author{
JURNAL KESEHATAN MASYARAKAT (e-Journal) \\ Volume 9, Nomor 6, November 2021 \\ ISSN: 2715-5617 / e-ISSN: 2356-3346 \\ http://ejournal3.undip.ac.id/index.php/jkm
}

Tabel 1. Hasil Pengukuran Parameter Lingkungan

\begin{tabular}{lllll}
\hline Pengulangan & Suhu $\left({ }^{\circ} \mathrm{C}\right)$ & Kelembaban $(\%)$ & $\begin{array}{l}\text { Intensitas } \\
\text { Cahaya }(\text { Lux })\end{array}$ & $\begin{array}{l}\text { Kecepatan Angin } \\
\text { (Km/jam) }\end{array}$ \\
\hline 1 & 29,7 & 78 & 1416 & 0,0 \\
2 & 29,7 & 78 & 1815 & 0,0 \\
3 & 31 & 85 & 2432 & 0,0 \\
4 & 31,5 & 88 & 1748 & 0,0 \\
5 & 30,6 & 73 & 1420 & 0,0 \\
6 & 28,7 & 86 & 2473 & 0,0 \\
\hline Rerata & 30,2 & 81,3 & 1884 & 0,0 \\
\hline
\end{tabular}

Pengukuran suhu lingkungan pada saat pengamatan di lokasi penelitian didapatkan rentang suhu antara $28^{\circ} \mathrm{C}-32^{\circ} \mathrm{C}$ dengan ratarata suhu untuk tiap pengulangan adalah $30,2^{\circ} \mathrm{C}$. Hal ini menunjukkan bahwa rentang suhu tersebut masih dalam rentang suhu optimal. Aktivitas optimal lalat terjadi pada rentang suhu $20^{\circ} \mathrm{C}-34^{\circ} \mathrm{C}$. aktivitas lalat akan berkurang pada rentang suhu $15^{\circ} \mathrm{C}-20^{\circ} \mathrm{C}$ atau pada rentang suhu $35^{\circ} \mathrm{C}-40^{\circ} \mathrm{C}$. Lalat akan mati atau tidak terdeteksi pada suhu di bawah $10^{\circ} \mathrm{C}$ dan suhu di atas $40^{\circ} \mathrm{C}$. Pada penelitian yang dilakukan oleh Agus Subagyo dkk tentang densitas dan identifikasi lalat di Pasar tradisional Purwokerto didapatkan hasil bahwa rata-rata suhu di Pasar Tradisional Purwokerto yaitu sekitar $29,1^{\circ} \mathrm{C} .{ }^{(9)}$

Pengukuran kelembaban lingkungan pada saat pengamatan di lokasi penelitian didapatkan rentang kelembaban antara $72 \%$ $88 \%$. Hal ini menunjukkan bahwa rentang tersebut masih dalam rentang kelembaban optimal. Aktivitas optimal lalat terjadi pada rentang kelembaban antara 45\% - 90\%. Kondisi suhu berkaitan dengan kelembaban dan berbanding terbalik. Apabila suhu di suatu lingkungan rendah maka kelembabannya akan tinggi dan jika suhunya tinggi maka kelembabannya akan rendah. Hal ini sejalan dengan penelitian Marsel Poluakan dkk tentang tingkat kepadatan lalat di Pasar Motoling Minahasa Selatan yag didapatkan hasil bahwa rentang kelembaban di tempat penjualan ikan dan daging Pasar Motoling terdapat pada rentang $57 \%-72 \% .{ }^{(10)}$

Pengukuran intensitas cahaya lingkungan pada saat pengamatan di lokasi penelitian didapatkan rentang intensitas cahaya antara 1400 Lux - 2500 Lux. Hal tersebut menunjukkan bahwa intensitas cahaya yang ada di lokasi penelitian termasuk sudah cukup tinggi. Lalat merupakan salah satu serangga yang bersifat fototropik atau menyukai cahaya, oleh karena itu lalat akan aktif sepanjang hari (diurnal) atau terdapat cahaya.(6) Semakin siang intensitas cahaya akan semakin tinggi dan berbanding lurus dengan suhu yang akan juga semakin tinggi, sedangkan kelembaban akan mengalami penurunan sehingga tidak optimal untuk lalat beraktivitas.

Pengukuran kecepatan angin lingkungan pada saat pengamatan di lokasi penelitian didapatkan sebesar $0 \mathrm{~km} / \mathrm{jam}$. Hal tersebut menunjukkan bahwa lalat dapat beraktivitas secara optimal karena tidak terdapat gangguan angin. Lalat sangat aktif mencari makanan dan akan mencari tempat untuk beristirahat pada lingkungan yang berangin tenang. Sedangkan lalat akan mengalami penuruan aktivitas pada lingkungan yang berangin kencang dan akan menghindari tempat peristirahatan yang berangin kencang. Kecepatan angin dikatakan tenang apabila besarnya terdapat pada rentang $0 \mathrm{~km} / \mathrm{jam}-1,5 \mathrm{~km} / \mathrm{jam} .{ }^{(6)}$

\section{Identifikasi Rerata Jumlah Lalat} Terperangkap

Dari penelitian yang sudah dilakukan di tempat penjualan ikan Pasar Tambak Lorok Kota Semarang didapatkan hasil bahwa jumlah keseluruhan lalat yang didapat selama penelitian dengan 6 kali pengulangan dan pemasangan perangkap selama 3 jam per pengulangan sebanyak 1827 ekor. 


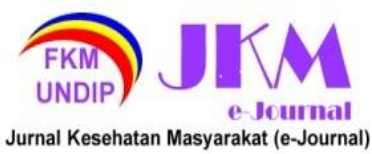

JURNAL KESEHATAN MASYARAKAT (e-Journal)

Volume 9, Nomor 6, November 2021

ISSN: 2715-5617 / e-ISSN: 2356-3346

http://ejournal3.undip.ac.id/index.php/jkm

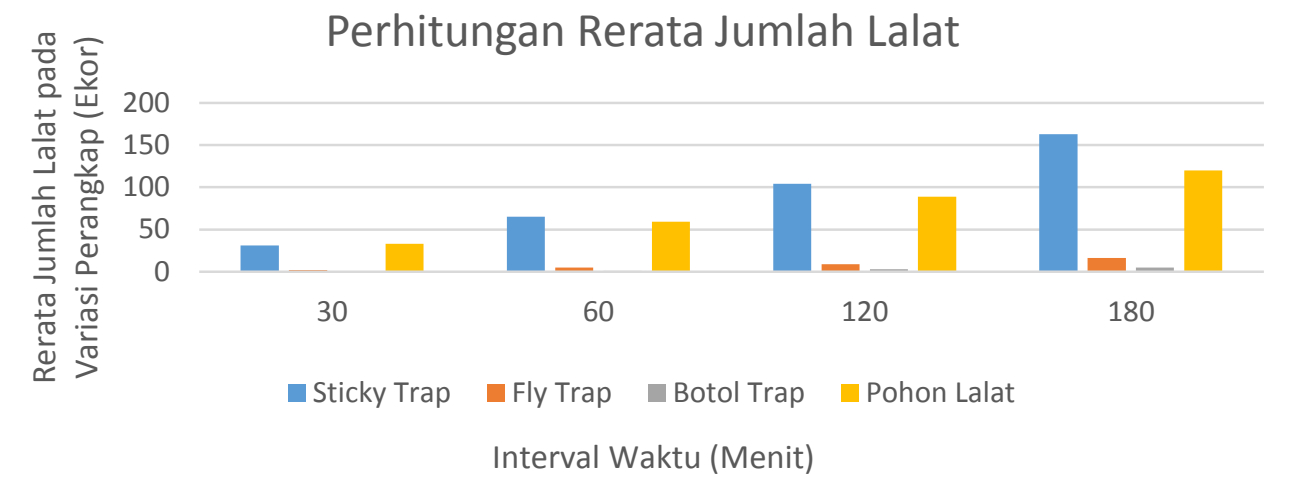

Gambar 1. Grafik Perhitungan Rerata Jumlah Lalat

Sedangkan rincian jumlah lalat yang didapatkan pada masing-masing perangkap lalat yang dipasang dari sticky trap, fly trap, botol trap, dan pohon lalat secara berturut-turut adalah 979 ekor, 97 ekor, 30 ekor, dan 721 ekor. Hal ini menunjukkan bahwa jenis perangkap yang dapat memerangkap lalat paling banyak adalah sticky trap.

Pada jenis perangkap sticky trap yang digunakan dalam penelitian ini dapat memerangkap lalat dengan jumlah terbanyak dibandingkan dengan jenis perangkap lalat yang lainnya yaitu fly trap, botol trap, dan pohon lalat. Lalat yang terperangkap pada sticky trap dengan 6 kali pengulangan didapatkan angka rerata sebanyak 163 ekor. Banyaknya lalat yang menempel pada sticky trap dimungkinkan karena jenis perangkap ini memiliki kelebihan yaitu berbentuk lembaran sehingga memiliki ruang atau tempat yang cukup lebar untuk lalat tersebut hinggap. Selain itu, sticky trap yang tersebar luas di pasaran berwarna kuning tua ataupun muda. Hal ini didukung oleh penelitian sebelumnya yang dilakukan oleh Sri Elen Husein pada tahun 2014 tentang pengaruh warna pada flygrill terhadap kepadatan lalat di Tempat Pelelangan Ikan Gorontalo didapatkan hasil bahwa lalat banyak hinggap pada flygrill dengan warna kuning.(11) Penggunaan sticky trap tidak memerlukan umpan untuk menarik lalat sehingga tergolong efektif digunakan untuk memerangkap lalat. Pada penelitian yang dilakukan oleh Desi 2018 tentang pengaruh pemakaian kertas lem sampah perasan ikan terhadap jumlah lalat terperangkp di TPS Terminal Baturraden dihasilkan bahwa penggunaan kertas lem tanpa umpan juga tetap dapat memerangkap lalat dengan jumlah yang banyak. ${ }^{(12)}$

Pada jenis perangkap fly trap yang dipasang dalam penelitian ini cukup dapat memerangkap lalat. Lalat yang terperangkap pada fly trap dengan 6 kali pengulangan didapatkan angka rerata sebanyak 16 ekor.
Rerata jumlah lalat yang terperangkap pada fly trap ini dipengaruhi oleh beberapa faktor. Fly trap merupakan jenis perangkap yang cocok digunakan di ruangan terbuka seperti tempat penjualan ikan Pasar Tambak Lorok. Fly Trap juga memiliki ruangan yang cukup besar yang dapat menampung lalat dengan jumlah banyak.fly trap ini juga harus diberi umpan untuk menarik lalat masuk ke dalam fly trap. Akan tetapi dimungkinkan bau atau aroma ikan yang ada di lokasi tersebut sangat kuat, sehingga apabila menggunakan fly trap dengan umpan apapun kemungkinan baunya akan kalah dengan bau yang terdapat pada tempat penjualan ikan. Fly trap yang terdapat di pasaran kebanyakan berwarna hijau. Sedangkan lalat lebih tertarik dengan warna kuning. ${ }^{(13)}$

Pada jenis perangkap botol trap yang dipasang dalam penelitian ini hanya dapat sedikit memerangkap lalat. Lalat yang terperangkap pada botol trap dengan 6 kali pengulangan didapatkan angka rerata hanya 5 ekor. Botol trap ini kurang cocok digunakan untuk memerangkap lalat di tempat penjualan ikan Pasar Tambak Lorok Kota Semarang. Botol trap tersebut sangat ramah lingkungan karena memanfaatkan botol bekas yang ada di lingkungan sekitar masyarakat. Akan tetapi botol trap memiliki ruang yang tidak terlalu besar sehingga kurang dapat memerangkap lalat dengan jumlah yang banyak. Selain itu botol trap juga membutuhkan umpan untuk menarik lalat agar masuk ke dalam botol. Seperti fly trap yang juga membutuhkan umpan, botol trap kurang efektif digunakan karena bau yang terdapat di tempat penjualan ikan tersebut lebih menyengat daripada umpan yang dipasang pada botol. Hal tersebut yang mungkin menjadi penyebab sedikitnya lalat yang terperangkap dalam botol trap. Sehingga penggunaan botol trap di pasar ini kurang cocok digunakan jika dibandingkan dengan penelitian yang dilakukan oleh Panditan 2019 


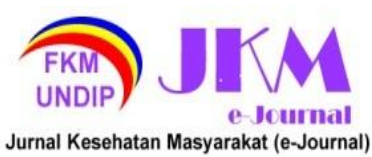

dihasilkan bahwa penggunaan perangkap lalat dengan botol dapat memerangkap lalat cukup banyak dengan rata-rata sekitar 280 ekor yang dilakukan di pemukiman.(14)

Pada perangkap jenis pohon lalat yang dipasang dalam penelitian ini dapat memerangkap lalat dengan jumlah yang cukup banyak. Lalat yang terperangkap pada pohon lalat dengan 6 kali pengulangan didapatkan angka rerata sebanyak 120 ekor. Terdapat beberapa faktor yang kemungkinan menjadi penyebab banyaknya rerata jumlah lalat yang terperangkap pada pohon lalat. Pohon lalat hampir memiliki persamaan dengan sticky trap yaitu cara kerjanya dengan menggunakan lem agar lalat yang hinggap menempel. Pohon lalat bersifat 3 dimensi yang banyak cabang seperti ranting-ranting pohon sehingga lalat dapat Tabel 2. Hasil Uji Kruskal Wallis bebas hinggap pada cabang pohon. oleh karena itu pohon lalat cukup efektif untuk digunakan memerangkap lalat di tempat penjualan ikan Pasar Tambak Lorok Kota Semarang. Pada penelitian yang dilakukan oleh Munandar 2018 dihasilkan bahwa dengan pemasangan pohon lalat dapat memerangkap lalat dengan jumlah yang banyak. ${ }^{(15)}$

\section{Pengaruh Variasi Perangkap Terhadap Jumlah Lalat Terperangkap}

Berdasarkan tabel 2. Hasil uji kruskal wallis didapatkan hasil bahwa nilai signifikansi sebesar 0.000 . Oleh karena nilai signifikansi $0.000>0.05$, maka sesuai dengan dasar pengambilan keputusan bahwa terdapat perbedaan yang signifikan antara pengaruh pengaplikasian variasi perangkap terhadap jumlah lalat yang terperangkap.

\begin{tabular}{ll} 
& Jumlah_Lalat \\
\hline Chi-Square & 19.981 \\
Df & 3 \\
Asymp. Sig. & .000 \\
\hline
\end{tabular}

a. Kruskal Wallis Test

b. Grouping Variable: Variasi_Perangkap

Variasi perangkap lalat yang dapat memerangkap lalat di tempat penjualan ikan Pasar Tambak Lorok dari yang terbanyak adalah sticky trap, pohon lalat, fly trap, dan botol trap. Penelitian yang sudah dilakukan sebelumnya oleh Windra 2015 tentang efektivitas 4 perangkap serangga dihasilkan bahwa sticky trap berwarna kuning cukup efektif memerangkap lalat.(16)

Hasil yang didapatkan pada penelitian ini yaitu jenis perangkap lalat sticky trap dapat memerangkap lalat dengan jumlah paling tinggi. Sehingga perangkap sticky trap dapat digunakan secara efektif untuk melakukan pengendalian lalat di tempat penjualan ikan Pasar Tambak Lorok Kota Semarang. Perangkap sticky trap ini juga dapat digunakan oleh para penjual ikan atau masyarakat sekitar karena aman, tidak mengandung bahan kimia, dan banyak ditemukan di pasaran.

\section{KESIMPULAN}

Berdasarkan hasil penelitian ini didapatkan bahwa terdapat perbedaan yang signifikan $(p=0.000)$ variasi perangkap terhadap jumlah lalat terperangkap di tempat penjualan ikan Pasar Tambak Lorok Kota Semarang. Jenis perangkap lalat yang dapat memerangkap lalat dengan jumlah paling banyak yaitu sticky trap. Sehingga penggunaan perangkap sticky trap dapat digunakan sebagai alternative untuk mengendalikan populasi lalat di tempat penjualan ikan Pasar Tambak Lorok Kota Semarang.

\section{UCAPAN TERIMA KASIH}

Ucapan terima kasih penulis sampaikan kepada Dinas Perdagangan Kota Semarang yang telah mengizinkan kegiatan penelitian di Pasar Tambak Lorok Kota Semarang. Para pengurus Pasar Tambak Lorok Kota Semarang yang telah memfasilitasi dan membantu dalam pengambilan data di lapangan. Serta para pedagang ikan yang turut mendukung kegiatan penelitian ini hingga selesai.

\section{DAFTAR PUSTAKA}

1. Andiarsa D. Lalat: Vektor yang Terabaikan Program? Balaba J Litbang Pengendali Penyakit Bersumber Binatang Banjarnegara. 2018;201-14.

2. Sucipto C.D. Vektor Penyakit Tropis. Yogyakarta: Gosyen Publishing; 2011.

3. Andiarsa D, Setianingsih I, Fadilly A, Hidayat S. Gambaran Bakteriologis Lalat dan Culicidae (Ordo: Diptera) di Lingkungan Balai Litbang P2B2 Tanah Bumbu. J Vektor Penyakit. 2016;9(2):37-44.

4. Sarwar M. Insect Borne Diseases 


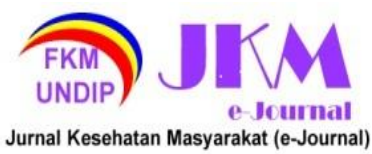

Transmitted By Some Important Vectors of Class Insecta Hurtling Public Health. Int $\mathrm{J}$ Bioinforma Biomed Eng. 2015;1(3):311-7.

5. Manalu Merylanca, Matsaulina Irnawati AT. Hubungan Tingkat Kepadatan Lalat (Musca domestica) dengan Kejadian Diare pada Anak Balita Di Pemukiman Sekitar Tempat Pembuangan Akhir Sampah Namo Bintang Kecamatan Pancur Batu Kabupaten Deli Serdang Tahun 2012. 2012;1-10.

6. Departemen Kesehatan Republik Indonesia. Pedoman Pengendalian Lalat. Jakarta: Direktorat Jenderal Pengendalian Penyakit dan Penyehatan Lingkungan Kementerian Kesehatan RI; 2014.

7. Permenkes Nomor 50. Standar Baku Mutu Kesehatan Lingkungan dan Persyaratan Kesehatan untuk Vektor dan Binatang Pembawa Penyakit Serta Pengendaliannya. Menteri Kesehat Republik Indones. 2017;(96):1-83.

8. Ikawati B, Sunaryo S, Widiastuti D. Peta Status Kerentanan Aedes aegypti (Linn.) Terhadap Insektisida Cypermethrin dan Malathion di Jawa Tengah. ASPIRATOR - J Vector-borne Dis Stud. 2015;7(1):238.

9. Subagyo A, Widyanto A, Santjaka A. Densitas dan Identifikasi Lalat serta Upaya Pengendaliannya di Pasar Tradisional Purwokerto. J Kesehat. 2013;4(3):483-91.

10. Poluakan M, Rumajar $\mathrm{P}$, Pakasi F. Tingkat Kepadatan Lalat di Pasar Motoling Kecamatan Motoling Kabupaten Minahasa Selatan. J Kesehat Lingkung. 2016;6(1):28-35.

11. Husein SE. Pengaruh Variasi Warna Fly Grill Terhadap Kepadatan Lalat di Tempat Pelelangan Ikan (TPI) Kota Gorontalo. UNG Repos. 2014;

12. Setianingsih D, Ramlan D. Pengaruh Pemakaian Kertas Lem Sampah Perasan Ikan Terhadap Jumlah Lalat Terperangkap Di TPS Terminal Baturraden Tahun 2018. J Sehat Mandiri. 2019;14(1):47-62.

13. Rustina W. Pengaruh Ketertarikan Hama Umbi Kentang TerhadapWarna Cahaya di Tempat Penyimpanan. Univ Bandung Raya. 2010;

14. Panditan E, Joy V.I. Sambuaga. Efektivitas Perangkap Lalat dari Botol Plastik Bekas Kemasan Air Mineral Dengan Menggunakan Variasi Umpan.

2019;9(1)

15. Munandar, M. Arief, Retno Hestiningsih NK. Perbedaan Warna Perangkap Pohon Lalat yang Terperangkap di Tempat Akhir (TPA) Sampah Jatibarang Kota Semarang. 2018;6:157-67.

16. Priawandriputra $W$, Permana AD. Efektifitas Empat Perangkap Serangga dengan Tiga Jenis Atraktan di Perkebunan Pala (Myristica fragrans Houtt). J Sumberd Hayati. 2016;1(2):549.

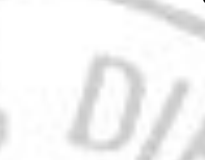

Volume 9, Nomor 6, November 2021

ISSN: 2715-5617 / e-ISSN: 2356-3346

http://ejournal3.undip.ac.id/index.php/jkm

(1)

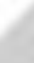

